\title{
Structural, thermal and energetic characteristics of synthetic active carbons prepared on the basis of ion-exchange resin Amberlite IRC 84
}

\author{
Barbara Charmas $^{1}$ (D) Karolina Kucio $^{1} \cdot$ Jadwiga Skubiszewska-Zięba $^{1} \cdot$ Svitlana Khalameida $^{2}$
}

Received: 13 April 2018/Accepted: 7 October 2018/Published online: 15 October 2018

(c) The Author(s) 2018

\begin{abstract}
A series of activated carbons was prepared from the ion-exchange resin (Amberlite IRC-84, Rohm and Haas) differing in $\mathrm{Ca}^{2+}$ content and studied by means of adsorption ( $\mathrm{N}_{2}$ adsorption) and thermogravimetric methods. Thermogravimetry was performed in two ways: classical and quasi-isothermal. Preparation processes proceeded in different conditions (temperature and atmosphere). This resulted in changes of their porosity and thermal stability. As shown by the studies, low temperature and calcium ion content are not suitable for obtaining carbon materials with desirable structural properties and good thermal resistance. $\mathrm{Ca}^{2+}$ ions increase makes it possible to obtain carbonaceous materials with a large specific surface area, well-developed porosity and high thermal stability. The quasi-isothermal thermogravimetric analysis allowed to characterize energetic and structural heterogeneity of active carbons. Changes in the free energies of adsorbed water layer during their desorption as well as dependence of the effective radius of a drop evaporated from the surface on the adsorbed water concentration were determined. The dependence $\mathrm{d} G / \mathrm{d} M_{\mathrm{H}_{2} \mathrm{O}}\left(\mathrm{C}_{\mathrm{H}_{2} \mathrm{O}}\right)$ was examined under the conditions of low coverage of carbon surfaces with the adsorbed water which may indicate formation of various types of water clusters on the surfaces.
\end{abstract}

Keywords Synthetic active carbons · Porosity $\cdot$ Thermogravimetry TG $\cdot$ Free surface energy $\cdot$ Quasi-isothermal method Q-TG · Surface heterogeneity

\section{Introduction}

Heavy metals are used in many industrial, technological and scientific areas. Impurities can be also a result of deionization of boiler water, usage of water in nuclear power plants and sewage treatment, etc. They are harmful for the natural environment. Removal of toxic and undesirable impurities from the environment is an essential problem. As follows from the investigations the use of ionexchange resins is an effective way to remove such contaminants [1-4]. Such spent resins undergo very slow degradation processes which may result in the emission of hazardous species into the environment. One of the

Barbara Charmas

barbara.charmas@poczta.umcs.lublin.pl

1 Faculty of Chemistry, Maria Curie-Skłodowska University, Maria Curie-Skłodowska Sq. 3, 20-031 Lublin, Poland

2 Institute for Sorption and Problems of Endoecology, NAS of Ukraine, Naumov Street 13, Kiev 03164, Ukraine alternative ways of utilization of such organic wastes is their carbonization and activation in order to prepare active carbons. Surface impurities can affect yield of carbon material pyrolysis as well as their mechanical and adsorption properties. On the other hand, certain additives to facilitate the carbonization process and improve the properties of the end product are frequently applied. They ensure stabilization and reinforcement of spatial structure of the initial polymer, to become finally an active site, attractive for different adsorption processes.

Synthetic carbon adsorbents prepared on the basis of porous copolymers or ion-exchange resins possess numerous interesting properties. The possibility of controlling chemical composition and pore size distribution of initial polymers permits developing surface and porosity of polymer-derived carbons. Such carbons have many advantages due to a set of unique properties, characteristic of this type of carbon, e.g., regular spherical shape of the granules, high mechanical strength and sorption capacity as well as high purity [5-7]. 
Properties of active carbons depend also on pyrolysis conditions, such as range of temperature, heating rate, atmosphere of carbonization and activation, etc. It is known, that, due to reproducibility of the process and predictability of the carbon parameters, one can obtain carbons, which can be used as catalyst supports [8], adsorbents in separation and purification processes [9] as well as adsorbents for gas storage [10].

The porous structure of synthetic active carbons consists of micro- and mesopores of different dimensions and low macropores volume. Traditional characterization $\left(\mathrm{N}_{2}\right.$ adsorption) has been mainly focused on the determination of specific surface area and the pore size distribution. But synthetic active carbons have also energetic heterogeneity caused by non-uniformity of porous structure and nonhomogeneity of chemical composition. Complementary characterization can be made using thermogravimetric analysis (TG), especially carried out under the quasiisothermal conditions (Q-TG). The method was developed by Paulik and Paulik [11, 12] and Rouquerol [13]. Thermal analysis was used to investigate various adsorbents, e.g., active carbons [14, 15], alumina [16], silica gels [17], soil [18] and composite materials [19, 20]. The authors [21] applied the thermogravimetric methods to examine the porous structure of the tested adsorbents, liquid films adsorbed on the surface of materials and energetic heterogeneity of silica surface.

\section{Experimental}

The aim of the paper was the discussion of possibilities of the $\mathrm{N}_{2}$ adsorption and TG/Q-TG methods to determine the characteristics of synthetic active carbons of different $\mathrm{Ca}^{2+}$ content. Special attention was paid to differentiated porosity and characterization of the interfacial water layers of porous adsorbents. In particular, it studies the effect of $\mathrm{Ca}^{2+}$ ions content and pyrolysis conditions on the structure and properties of hydration layers formed on the complex surfaces of polymer-derived active carbon.

Materials Carbon sorbents were prepared from the ionexchange acryl resin Amberlite IRC-84 in the calcium form. The initial resin (sodium form) in the spherical grains form was subjected to swelling and converted into the hydrogen form $(2 \mathrm{M} \mathrm{HCl})$. Then the resin in the hydrogen form was subjected to the next ion exchange to obtain a calcium form. During the ion-exchange process there were applied aqueous solutions of calcium acetate of the concentrations: $0.04 \mathrm{M} 0.1 \mathrm{M}$ and $1 \mathrm{M}$. Then the resin grains were washed with distilled water in order to remove the acetate ions and dried at $110{ }^{\circ} \mathrm{C}$ for $12 \mathrm{~h}$. The obtained resin forms were characterized by different contents of deposited calcium ions, i.e., $0.5,1.9$ and $5.6 \%$ by mass after impregnation with $0.04 \mathrm{M}, 0.1 \mathrm{M}$ and $1 \mathrm{M}$ solutions.

Carbonization Carbonization and activation were performed in the flow quartz reactor. The samples were placed in the heating coat controlled by the temperature programming device Shiamaden FP 21. The inert gas (He) flow rate was $0.5 \mathrm{dm}^{3} \mathrm{~min}^{-1}$. Carbonization was performed at $430{ }^{\circ} \mathrm{C}$. The obtained carbonizates were denoted: $\mathrm{C}-\mathrm{Ca}_{004}, \mathrm{C}-\mathrm{Ca}_{01}$ and $\mathrm{C}-\mathrm{Ca}_{1}$ where $\mathrm{C}$ is the carbonizate, $\mathrm{Ca}$ - the calcium form of the initial resin, 004, 01 and 1the concentrations of the $\mathrm{Ca}\left(\mathrm{CH}_{3} \mathrm{COO}\right)_{2}$ solutions used for impregnation.

Stripping Before further activation carbonizates were washed clean from unbound $\mathrm{Ca}^{2+}$ ions and organic impurities which did not undergo decomposition or pyrolysis. During washing of carbonizates with the $2 \mathrm{M} \mathrm{HCl}$ solution the filtrate color changed from dark brown, indicating the presence of uncarbonized organic compound to colorless. Next the materials were washed with distilled water till neutral $\mathrm{pH}$ was obtained and then dried.

Activation The washed off carbonizates were activated. Thermal activation was carried out in the helium atmosphere $\left(0.5 \mathrm{dm}^{3} \min ^{-1}\right)$ or using the reaction mixture $\mathrm{H}_{2} /$ $\mathrm{He}$ of the total gas flow intensity $0.5 \mathrm{dm}^{3} \mathrm{~min}^{-1}$ $\left(0.05 \mathrm{dm}^{3} \min ^{-1}-\mathrm{H}_{2}, 0.45 \mathrm{dm}^{3} \mathrm{~min}^{-1}-\mathrm{He}\right)$. The process proceeded at $800{ }^{\circ} \mathrm{C}$. The obtained active carbons (AC) were denoted $\mathrm{AC}-\mathrm{Ca}_{004}-\mathrm{He}, \mathrm{AC}-\mathrm{Ca}_{01}-\mathrm{He}$ and $\mathrm{AC}-$ $\mathrm{Ca}_{1}-\mathrm{He}$ (activated in the helium atmosphere) and $\mathrm{AC}-$ $\mathrm{Ca}_{004}-\mathrm{H}_{2}, \mathrm{AC}-\mathrm{Ca}_{01}-\mathrm{H}_{2}$ and $\mathrm{AC}-\mathrm{Ca}_{1}-\mathrm{H}_{2}$ (activated in the $\mathrm{H}_{2} / \mathrm{He}$ mixture). For comparison the effects of the temperature and $\mathrm{Ca}^{2+}$ ions content on the structural parameters of the obtained materials, the resin saturated with calcium acetate $(1 \mathrm{M})$ was pyrolized and activated in a continuous way (in the He atmosphere without the intermediate stage of $\mathrm{Ca}^{2+}$ ions washing off) at $730{ }^{\circ} \mathrm{C}$. The obtained active carbon was denoted $\mathrm{AC}-\mathrm{Ca}_{1}-\mathrm{He}^{*}$.

\section{Textural characteristics}

$\mathrm{N}_{2}$ adsorption/desorption isotherms were recorded at $-196{ }^{\circ} \mathrm{C}$ by means of a Micromeritics ASAP $2405 \mathrm{~N}$ adsorption analyzer. The specific surface area $S_{\mathrm{BET}}$ was calculated using the standard BET equation [22] at $p / p_{\mathrm{o}}$ between 0.06 and 0.2 (where $p$ and $p_{\mathrm{o}}$ denote the equilibrium and saturation pressures of nitrogen, respectively). The pore volume $V_{\mathrm{p}}$ was estimated under the relative pressure $p / p_{\mathrm{o}} \approx 0.98$. The average pore radius $\left(R_{\mathrm{av}}\right)$ was calculated for a model of cylindrical pores $R_{\mathrm{av}}=2 V_{\mathrm{p}} / S_{\mathrm{BET}}$. The nitrogen desorption data were used to calculate the $\mathrm{d} V /$ $\mathrm{d} R$ and $\mathrm{d} S / \mathrm{d} R$ dependencies using the procedure described elsewhere [23]. The values and contributions (\%) of micro( $V_{\text {micro }}$ and $S_{\text {micro }}$ at $\left.R<1 \mathrm{~nm}\right)$, meso- $\left(V_{\text {meso }}\right.$ and $S_{\text {meso }}$ at 
$1<R<25 \mathrm{~nm}$ ), and macropores ( $V_{\text {macro }}$ and $S_{\text {macro }}$ at $25<R<100 \mathrm{~nm}$ ) were determined [24-27].

\section{Thermal analysis}

Thermal analysis of the carbons samples was carried out using Derivatograph C (Paulik, Paulik and Erdey, MOM, Hungary) with the linear heating rate of $10^{\circ} \mathrm{C} \mathrm{min}^{-1}$ in the air atmosphere in the temperature range from 20 to $1000{ }^{\circ} \mathrm{C}$. During investigations the TG, DTG and DTA curves were registered. The measurements were taken using korund crucibles and alumina as the reference material. The TG data were used to estimate the carbon content $\left(\mathrm{C}_{\mathrm{C}}\right)$ and thermal stability of carbons. The measurement error using the DTA method is $\pm 5 \%$.

\section{Quasi-isothermal desorption of water}

The quasi-isothermal thermogravimetric analysis was applied to study the structure of water layers adsorbed on the carbon adsorbent surface. This way of interpretation of the data obtained using the quasi-isothermal thermogravimetric method allows to characterize energetic and structural heterogeneity of adsorbent surfaces. Synthetic active carbons were characterized from the changes in the free energies of adsorbed water layer during their desorption as well as dependence of the effective radius of a drop evaporated from the surface on the adsorbed water concentration. Dependence $\mathrm{d} G / \mathrm{d} M_{\mathrm{H}_{2} \mathrm{O}}\left(\mathrm{C}_{\mathrm{H}_{2} \mathrm{O}}\right)$ was examined under the conditions of low coverage of the adsorbent surface with the adsorbed water, which can indicate the formation of various types of water clusters on the surfaces.

Thermodesorption of water from the surface of investigated samples was additionally carried out under quasiisothermal conditions (Q-TG) in the range of $20-300{ }^{\circ} \mathrm{C}$ using a Derivatograph C (Paulik, Paulik and Erdey, MOM, Hungary). Prior to Q-TG analysis the samples were poured with redistilled water, subjected to ultrasound in an ultrasonic bath for $30 \mathrm{~s}$ and then left for $24 \mathrm{~h}$. After impregnation the sample was gently dried from excess water so as not to empty the interior of the pores. After such drying, the materials contained a varied amount of excess water which was taken into account in further calculations. Then the weighed portions (about $25 \mathrm{mg}$ ) of adsorbents were placed in the special spherical platinum crucible of the derivatograph. $\mathrm{Al}_{2} \mathrm{O}_{3}$ was used as the reference material.

The experimental data of quasi-thermogravimetric measurements correspond to the water mass loss in accordance with temperature changes. When measurements are taken over a temperature range without any chemical reactions leading to changes in the sample mass, then the $\Delta m=f(T)$ dependence reflects changes in concentration of the water present on the adsorbent surface under equilibrium. These data were used as initial ones for calculation of energetic characteristics of the tested samples. This method was described precisely in [28]. On the basis of the obtained data, total concentrations of water adsorbed on the surface of studied adsorbents $(\mathrm{mg} / \mathrm{g}$ ) were calculated. The number of statistical monolayers " $n$ " of water was determined from Eq. (1):

$n=\mathrm{TG}_{\max } N \omega / S_{\mathrm{BET}} M$

where $\mathrm{TG}_{\max }$ - the maximum mass loss at $300{ }^{\circ} \mathrm{C}$ $\left(\mathrm{mg} \mathrm{g}^{-1}\right), \quad N$-the Avogadro number, $\omega$-the surface occupied by one adsorbed water molecule (assumed $\left.0.09 \mathrm{~nm}^{2}\right), S_{\mathrm{BET}}$ - the specific surface area of the tested adsorbents $\left(\mathrm{m}^{2} \mathrm{~g}^{-1}\right), M$-the molar mass of water $\left(18 \mathrm{~g} \mathrm{~mol}^{-1}\right)$.

\section{X-ray fluorescence spectrometry with dispersion of energy (ED-XRF)}

Calcium ions concentration was determined by means of a fluorescence spectrometer Camberra Packard equipped with the radioisotope sources: ${ }^{109} \mathrm{Cd},{ }^{55} \mathrm{Fe},{ }^{241} \mathrm{Am}$. The spectrometer was equipped with a semiconductor detector $\mathrm{Si}(\mathrm{Li})$ working at the liquid nitrogen temperature.

\section{Determination of macropores volume}

The total pores volume $\left(V_{\text {total* }}\right)$ and macropores volume ( $\left.V_{\text {macro* }}\right)$ were determining by their filling with methanol. The dried $\left(110{ }^{\circ} \mathrm{C}\right)$ carbon samples $\left(m_{\mathrm{p}} \sim 0.15 \mathrm{~g}\right)$ were put into cone flash, and methanol was added in small batches (using $1 \mathrm{~cm}^{3}$ volume burette). The pores filling process was ultrasound-aided. The drying and titration procedures were repeated several times, and the results were averaged. The volume of macropores $\left(V_{\text {macro** }}\right)$ was determined from Eq. 2:

$V_{\text {macro }^{*}}=V_{\text {total }^{*}}-V_{\mathrm{p}}$

where $V_{\mathrm{p}}$ - the volume of sorption pores obtained from the $\mathrm{N}_{2}$ adsorption/desorption data, *-the data obtained from the titration with methanol.

\section{Results and discussion}

\section{Textural characterization}

Table 1 presents the parameters of the porous structure obtained for carbonizates and active carbons prepared on the basis of the ion-exchange resin Amberlite IRC-84 impregnated with calcium acetate solutions of the concentrations: $0.04 \mathrm{M} ; 0.1 \mathrm{M}$ and $1 \mathrm{M}$. The materials were characterized by the increasing content of $\mathrm{Ca}^{2+}$ ions being 
Table 1 Parameters of the porous structure of activated carbons

\begin{tabular}{llllllllll}
\hline Sample & $\begin{array}{l}\mathrm{Ca} \% / \mathrm{w} / \\
\mathrm{w}\end{array}$ & $\begin{array}{l}S_{\mathrm{BET}} / \\
\mathrm{m}^{2} \mathrm{~g}^{-1}\end{array}$ & $\begin{array}{l}V_{\text {micro }} / \\
\mathrm{cm}^{3} \mathrm{~g}^{-1}\end{array}$ & $\begin{array}{l}\% V_{\text {micro }} / \\
\%\end{array}$ & $\begin{array}{l}V_{\text {meso }} / \\
\mathrm{cm}^{3} \mathrm{~g}^{-1}\end{array}$ & $\begin{array}{l}\% V_{\text {mes }} / \\
\%\end{array}$ & $\begin{array}{l}V_{\mathrm{p}} / \\
\mathrm{cm}^{3} \mathrm{~g}^{-1}\end{array}$ & $\begin{array}{l}V_{\text {total }} / \\
\mathrm{cm}^{3} \mathrm{~g}^{-1}\end{array}$ \\
\hline $\mathrm{C}-\mathrm{Ca}_{004}$ & 0.5 & 3.7 & 0.000 & 0.0 & 0.002 & 40.1 & 0.006 & 0.158 & $\begin{array}{l}V_{\text {macro* }} / \\
\mathrm{cm}^{3} \mathrm{~g}^{-1}\end{array}$ \\
$\mathrm{AC}-\mathrm{Ca}_{004}-\mathrm{He}$ & 0.5 & 2.7 & 0.007 & 99.2 & 0.000 & 0.8 & 0.007 & 0.146 & 0.152 \\
$\mathrm{AC}-\mathrm{Ca}_{004}-\mathrm{H}_{2}$ & 0.5 & 0.1 & 0.004 & 100.0 & 0.000 & 0.0 & 0.004 & 0.353 & 0.137 \\
$\mathrm{C}-\mathrm{Ca}_{01}$ & 1.9 & 3.6 & 0.000 & 0.0 & 0.004 & 26.8 & 0.002 & 0.225 & 0.349 \\
$\mathrm{AC}-\mathrm{Ca}_{01}-\mathrm{He}$ & 1.9 & 304.2 & 0.076 & 23.0 & 0.248 & 75.2 & 0.33 & 0.478 & 0.149 \\
$\mathrm{AC}-\mathrm{Ca}_{01}-\mathrm{H}_{2}$ & 1.9 & 297.9 & 0.080 & 25.8 & 0.222 & 71.2 & 0.30 & 0.505 & 0.208 \\
$\mathrm{C}-\mathrm{Ca}_{1}$ & 5.6 & 2.2 & - & - & - & - & 0.003 & 0.395 & 0.392 \\
$\mathrm{AC}-\mathrm{Ca}_{1}-\mathrm{He}$ & 5.6 & 540.3 & 0.133 & 9.8 & 0.659 & 48.5 & 1.21 & 2.318 & 1.196 \\
$\mathrm{AC}-\mathrm{Ca}_{1}-\mathrm{H}_{2}$ & 5.6 & 685.8 & 0.172 & 11.1 & 0.794 & 51.1 & 1.33 & 2.966 & 1.633 \\
$\mathrm{AC}-\mathrm{Ca}_{1}-\mathrm{He}^{*}$ & 5.6 & 684.0 & 0.165 & 11.1 & 0.628 & 42.2 & 1.16 & 2.656
\end{tabular}

$\% V_{\text {micro }}=\left(V_{\text {micro }} / V_{\mathrm{p}}\right) \times 100 \% ; \% V_{\text {meso }}=\left(V_{\text {meso }} / \mathrm{V}_{\mathrm{p}}\right) \times 100 \% ; V_{\mathrm{p}}$-total volume of sorption pores, $V_{\text {total* }}$-total pores volume determined using methanol, $V_{\text {macro* }}$-macropores volume determined using methanol

$0.5 ; 1.9$ and $5.6 \% \mathrm{w} / \mathrm{w}$, respectively. The analysis of the presented data indicates that carbonization of the resin in the calcium form at $430{ }^{\circ} \mathrm{C}$ results in the formation of carbonaceous materials of poorly developed surface area and porosity. The obtained carbonizates are characterized by the specific surface area from $2.2 \mathrm{~m}^{2} \mathrm{~g}^{-1}\left(\mathrm{C}-\mathrm{Ca}_{1}\right)$ to $3.7 \mathrm{~m}^{2} \mathrm{~g}^{-1}\left(\mathrm{C}-\mathrm{Ca}_{004}\right)$ which is associated, among others, with a small extent of carbonization of the obtained materials which contain large amounts of the organic substances not bound to the surface. This material fills the pores and deposits on the surface blocking it against the adsorbate $\left(\mathrm{N}_{2}\right)$ access.

Activation of washed off carbonizates carried out in both $\mathrm{He}$ atmosphere and $\mathrm{H}_{2} / \mathrm{He}$ mixture resulted in intensive development of porous structure (Table 1). At the same time a significant effect of calcium ions content on porous structure development was observed. In the case of impregnation with the calcium acetate of the concentration $0.04 \mathrm{M}\left(0.5 \% \mathrm{Ca}^{2+}\right)$ no carbonaceous materials of developed structure were obtained. With the increasing calcium ions content the specific surface area increases. This indicates that the $\mathrm{Ca}$ ions content $0.5 \%$ is not sufficient for preparing carbonaceous materials of good structural parameters and the $\mathrm{Ca}^{2+}$ content affects significantly development of porous structure of the obtained carbonaceous materials which is also confirmed by the analysis of the other parameters (e.g., $V_{\mathrm{p}}, V_{\text {micro }}, V_{\text {meso }}$ ) presented in Tables 1 and 2. The analysis of the presented data (Tables 1,2) shows that atmosphere is an essential factor of activation. For the $\mathrm{AC}-\mathrm{Ca}_{01}$ series $\left(1.9 \% \mathrm{Ca}^{2+}\right)$ better structural parameters were obtained after pyrolysis in the He atmosphere (Table 1). However, for the materials of the $\mathrm{Ca}^{2+}=5.6 \%$ content, the $\mathrm{H}_{2} / \mathrm{He}$ atmosphere proved to be more favorable as can be seen in Fig. 1 .

As already mentioned, for comparison of temperature and $\mathrm{Ca}^{2+}$ ions content effects on active carbon structural parameters, the resin impregnated with calcium acetate ( $1 \mathrm{M})$ was pyrolized and activated in a continuous way
Table 2 Parameters of the porous structure of activated carbons

\begin{tabular}{lllllll}
\hline Sample & $S_{\text {micro }} / \mathrm{m}^{2} \mathrm{~g}^{-1}$ & $\% S_{\text {micro }} / \%$ & $S_{\text {meso }} / \mathrm{m}^{2} \mathrm{~g}^{-1}$ & $\% S_{\text {meso }} / \%$ & $\Delta w$ & $R_{\text {av }} / \mathrm{nm}$ \\
\hline $\mathrm{C}-\mathrm{Ca} 004$ & 0.0 & 0.0 & 3.5 & 95.9 & 1.370 & 5.83 \\
$\mathrm{AC}-\mathrm{Ca}_{004}-\mathrm{He}$ & 2.7 & 99.5 & 0.0 & 0.5 & 1.588 & 5.45 \\
$\mathrm{AC}-\mathrm{Ca}_{004}-\mathrm{H}_{2}$ & 0.1 & 100 & 0.0 & 0 & -0.111 & - \\
$\mathrm{C}-\mathrm{Ca}_{01}$ & 0.0 & 0.0 & 3.4 & 94.3 & 1.385 & 9.26 \\
$\mathrm{AC}-\mathrm{Ca}_{01}-\mathrm{He}$ & 188.3 & 61.9 & 115.8 & 38.1 & 1.003 & 3.66 \\
$\mathrm{AC}-\mathrm{Ca}_{01}-\mathrm{H}_{2}$ & 190.4 & 63.9 & 107.4 & 36.0 & 1.003 & 3.52 \\
$\mathrm{C}-\mathrm{Ca}_{1}$ & - & - & - & - & - & 2.35 \\
$\mathrm{AC}-\mathrm{Ca}_{1}-\mathrm{He}$ & 339.9 & 62.9 & 170.0 & 31.5 & 1.002 & 2.48 \\
$\mathrm{AC}-\mathrm{Ca}_{1}-\mathrm{H}_{2}$ & 447.2 & 65.2 & 206.1 & 30.1 & 1.002 & 2.45 \\
$\mathrm{AC}-\mathrm{Ca}_{1}-\mathrm{He}$ & 431.3 & 63.1 & 214.5 & 31.4 & 1.001 & 2.67 \\
\hline
\end{tabular}

$\% S_{\text {micro }}=\left(S_{\text {micro }} / S_{\mathrm{BET}}\right) \times 100 \% ; \% S_{\text {meso }}=\left(S_{\text {meso }} / S_{\mathrm{BET}}\right) \times 100 \% ; \Delta w$-parameter defining the deviation from the assumed pore shape model: $\Delta w=\frac{S_{\mathrm{BET}}}{S_{\mathrm{sum}}-1}$ 


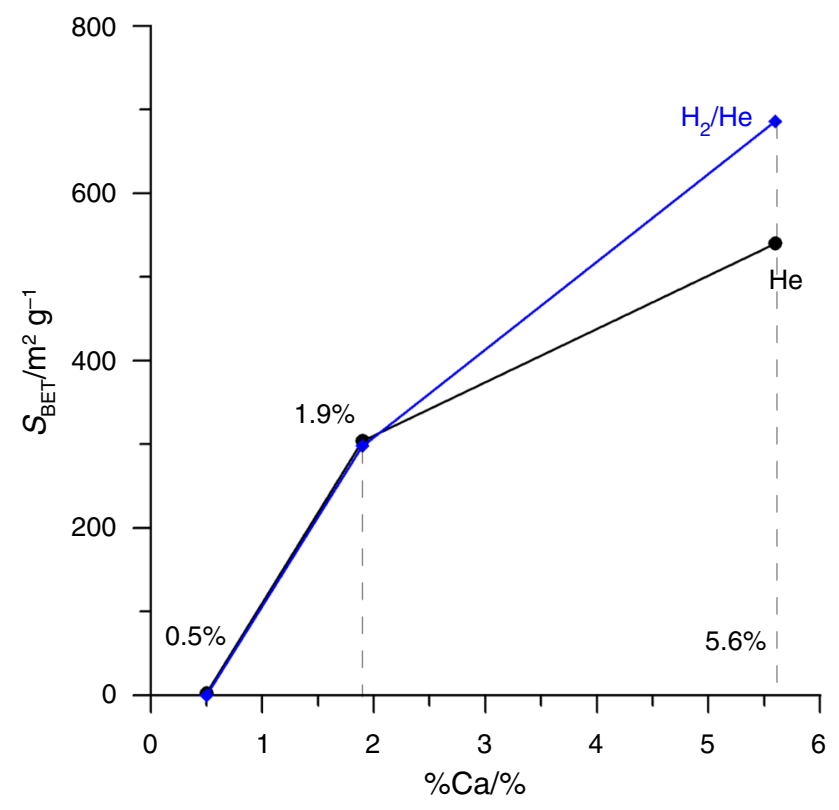

Fig. 1 Effect of activation atmosphere on the extent of active carbon surface development

(without the intermediate washing off state) at $730{ }^{\circ} \mathrm{C}$. The obtained active carbon was denominated $\mathrm{AC}-\mathrm{Ca}_{1}-\mathrm{He}^{*}$. The analysis of the structural parameters of the abovementioned carbon indicates that it possesses a well-developed specific surface area $\left(S_{\mathrm{BET}}=684 \mathrm{~m}^{2} \mathrm{~g}^{-1}\right)$ and micropore volume $\left(V_{\text {micro }}=0.165 \mathrm{~cm}^{3} \mathrm{~g}^{-1}, \% V_{\text {micro- }}\right.$ $=11.1 \%)$. The obtained results are comparable with the parameters obtained for the carbon $\mathrm{AC}-\mathrm{Ca}_{1}-\mathrm{H}_{2}$; however, the carbon $\mathrm{AC}-\mathrm{Ca}_{1}-\mathrm{He}^{*}$ is characterized by smaller contribution of mesopores $\left(\% V_{\text {meso }}=42.2 \%\right)$.

Enlargement of specific surface area is closely connected with development of pores structure. The analysis of the data obtained for the $\mathrm{AC}-\mathrm{Ca}_{004}$ series carbons indicates that these materials do not satisfy the requirements for the adsorbents (developed specific surface area and porosity). The other activates (AC-Ca $\mathrm{C}_{01}$ and $\mathrm{AC}-\mathrm{Ca}_{1}$ series) possess a well-developed porous structure. Contribution of micro- $\left(\% V_{\text {micro }}\right)$ and mesopores $\left(\% V_{\text {meso }}\right.$, Table 1$)$ is much greater for the $\mathrm{Ca}_{01}$ series $\left(\% \mathrm{Ca}^{2+}=1.9 \%\right.$, samples $\mathrm{AC}-\mathrm{Ca}_{01}-\mathrm{He}$ and $\left.\mathrm{AC}-\mathrm{Ca}_{01}-\mathrm{H}_{2}\right)$ being about $\sim 24 \%\left(\% V_{\text {micro }}\right)$ and $\sim 73 \%$ $\left(\% V_{\text {meso }}\right)$ (Table 1$)$. These adsorbents do not practically contain macropores (Table 1). In the case of active carbons of $\mathrm{Ca}^{2+}=5.6 \% \quad\left(\mathrm{AC}-\mathrm{Ca}_{1}\right.$ series$)$, the contribution of micropores volume is about $10.7 \%$, but of mesopores about $47 \%$. These carbons are characterized by large volume of macropores, and the largest volume $V_{\text {macro* }}$ was determined for the active carbon $\mathrm{AC}-\mathrm{Ca}_{1}-\mathrm{H}_{2}\left(1.633 \mathrm{~cm}^{3} \mathrm{~g}^{-1}\right.$, Table 1$)$, whereas the contribution of the surfaces $\% S_{\text {micro }}$ and $\% S_{\text {meso }}$ for all active carbons under discussion, independent of $\mathrm{Ca}$ ions content, is similar and amounts to about $62 \%\left(\% S_{\text {micro }}\right)$ and about $35 \%\left(\% S_{\text {meso }}\right.$, Table 2$)$.
For the studied adsorbents there were determined the parameters $\Delta w$ indicating deviation from the assumed model of pores shape (assumption about the cylindrical shape of pores). These values (Table 2) are close to 1 for the active carbons of $\mathrm{AC}-\mathrm{Ca}_{01}$ and $\mathrm{AC}-\mathrm{Ca}_{1}$ series, but they differ significantly from 1 for carbonizates and active carbons of the minimal calcium ions content $(\% \mathrm{Ca}=0.5 \%$, Table 2). Such values of $\Delta w$ parameters evidence the presence of pores of the shape different from the cylindrical one which confirms the earlier statement about a great effect of $\mathrm{Ca}^{2+}$ concentration on development of porous structure of synthetic active carbons.

Figures 2 and 3 present the low-temperature $\mathrm{N}_{2}$ adsorption/desorption isotherms as well as the $\mathrm{d} V / \mathrm{d} R$ and $\mathrm{d} S / \mathrm{d} R$ curves obtained for the active carbons of the AC$\mathrm{Ca}_{01}$ (Fig. 2) and $\mathrm{AC}-\mathrm{Ca}_{1}$ (Fig. 3) series. The $\mathrm{N}_{2}$

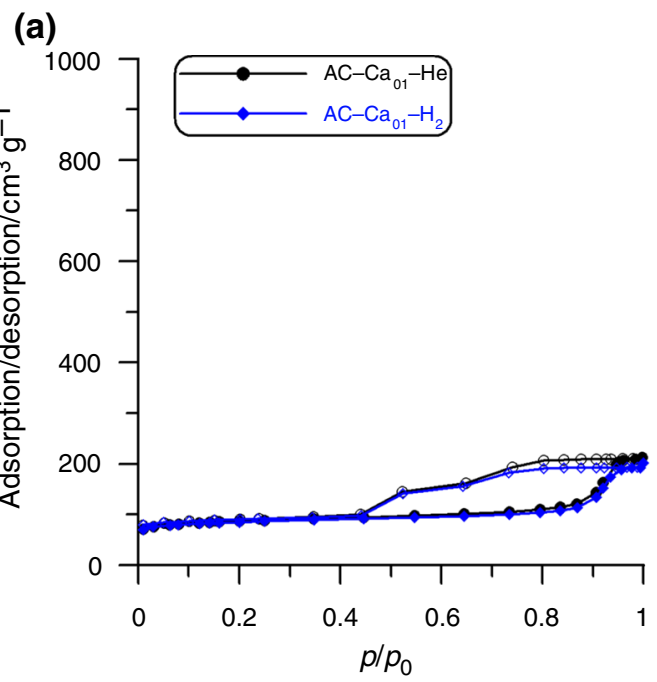

(b)

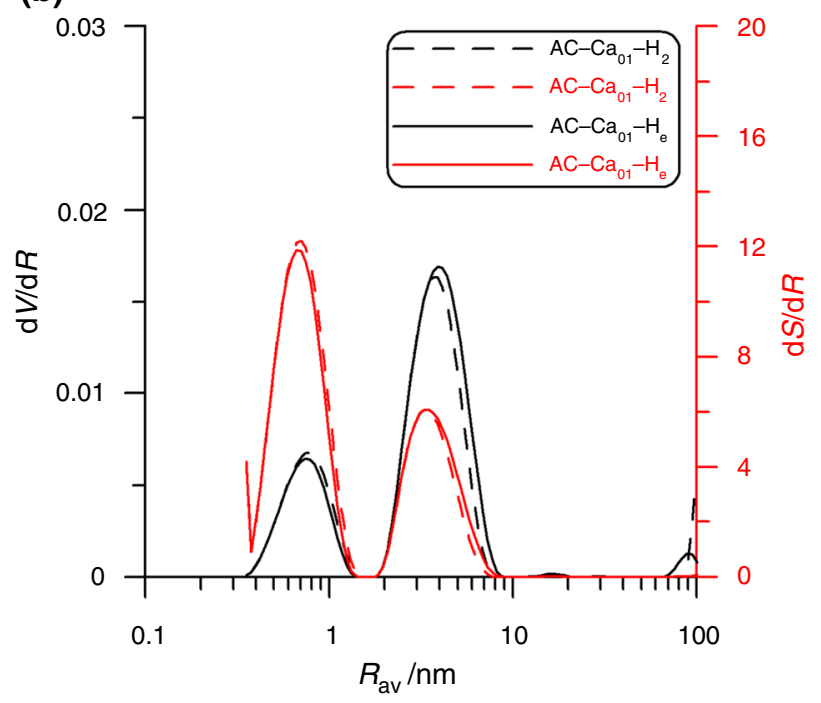

Fig. 2 Isotherms of $\mathrm{N}_{2}$ adsorption/desorption (a) and the curves of distribution of volume $\mathrm{d} V / \mathrm{d} R$ and surface $\mathrm{d} S / \mathrm{d} R$ of pores (b) for active carbons $\mathrm{AC}-\mathrm{Ca}_{01}-\mathrm{He}$ and $\mathrm{AC}-\mathrm{Ca}_{01}-\mathrm{H}_{2}$ 
(a)

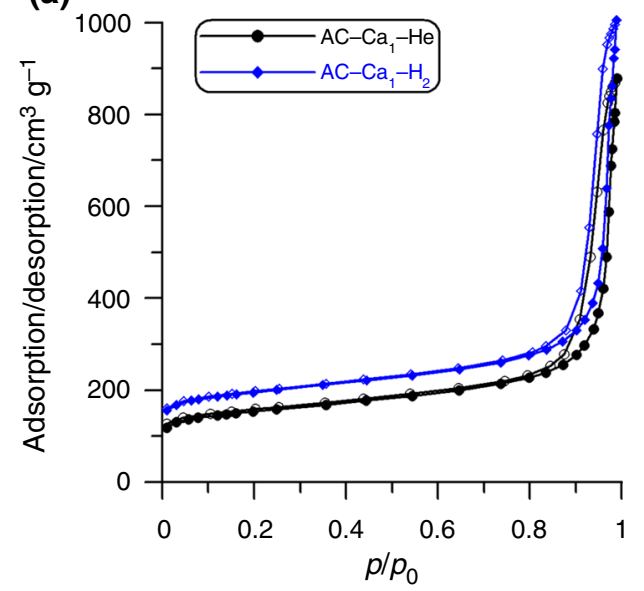

(c)

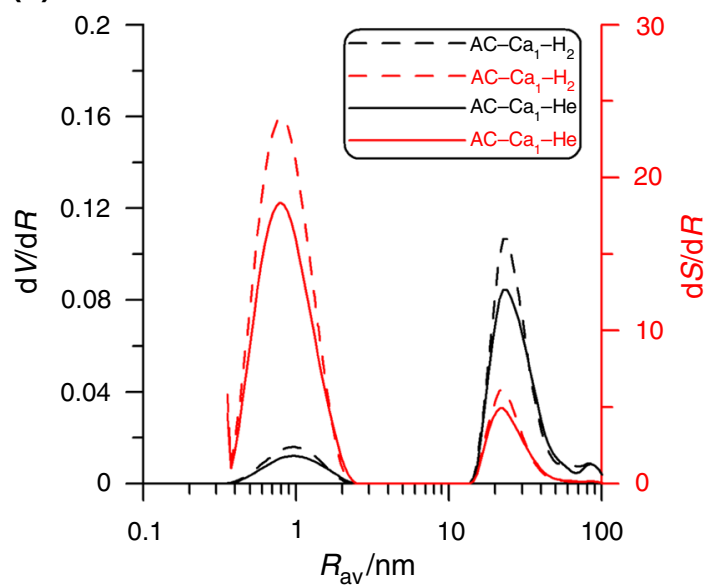

(b)

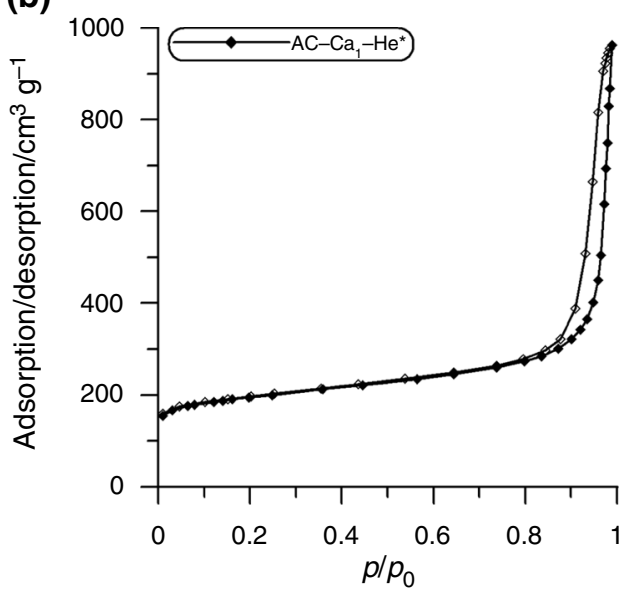

(d)

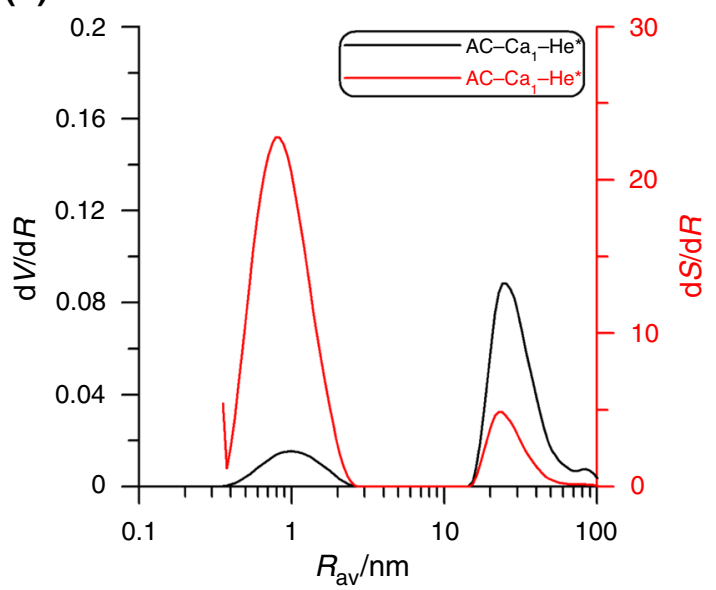

Fig. 3 Isotherms of $\mathrm{N}_{2}$ adsorption/desorption $(\mathbf{a}, \mathbf{b})$ and the curves of distribution of volume $\mathrm{d} V / \mathrm{d} R$ and surface $\mathrm{d} S / \mathrm{d} R$ of pores $(\mathbf{c}, \mathbf{d})$ for active carbons $\mathrm{AC}-\mathrm{Ca}_{1}-800 \mathrm{He}$ and $\mathrm{AC}-\mathrm{Ca}_{1}-800 \mathrm{H}_{2}(\mathbf{a}, \mathbf{c})$ as well as $\mathrm{AC}-\mathrm{Ca}_{1}-730^{*}(\mathbf{b}, \mathbf{d})$

adsorption/desorption isotherms for $\mathrm{AC}-\mathrm{Ca}_{01}$ carbons series (Fig. 2a) possess poorly developed hysteresis loop in the area $p / p_{\mathrm{o}}$ from 0.5 to 1 . The values at $p / p_{\mathrm{o}}=1$ indicate relatively low adsorption in mesopores. As follows from the shape of the isotherms and the pore volume and surface distribution curves (Fig. 2b), these adsorbents are characterized by a complex structure of pores. Some of them occur in the micropore range $\left(\% V_{\text {micro }}=23\right.$ and $25.8 \%$ for $\mathrm{AC}-\mathrm{Ca}_{01}-\mathrm{He}$ and $\mathrm{AC}-\mathrm{Ca}_{01}-\mathrm{H}_{2}$, respectively, $\% S_{\text {micro }} \sim 63 \%$ ), and others in the mesopores area $\left(\% V_{\text {meso }} \sim 73 \%, \% \mathrm{~S}_{\text {meso }} \sim 37 \%\right.$, Tables 1,2$)$. Moreover, the $\mathrm{d} V / \mathrm{d} R$ curves obtained for the carbon $\mathrm{AC}-\mathrm{Ca}_{01}-\mathrm{H}_{2}$ (Fig. 2b) show the third poorly developed maximum at $R_{\mathrm{av}}=90-100 \mathrm{~nm}$. The radii of dominating pores are $0.6 \mathrm{~nm}$ and $\sim 4 \mathrm{~nm}$.

In turn, the carbons of the $\mathrm{AC}-\mathrm{Ca}_{1}$ series are characterized by much better developed porous structure in both micro- and mesopores areas. The shape of the isotherms (Fig. 3) is very similar independent of activation atmosphere. Larger volumes $\left(V_{\text {micro }}\right)$ and surfaces $\left(S_{\text {micro }}\right.$ and $S_{\mathrm{BET}}$ ) are determined for these materials compared to the $\mathrm{AC}-\mathrm{Ca}_{01}$ carbons series. However, the contribution of micro- and mesopores is smaller than for the $\mathrm{AC}-\mathrm{Ca}_{01}$ series samples. This is due to the fact that the specific surface areas of the carbons $\mathrm{AC}-\mathrm{Ca}_{1}-\mathrm{He}$ and $\mathrm{AC}-\mathrm{Ca}_{1}-\mathrm{H}_{2}$ are much larger (Table 1). The curves of volume and pore surfaces distribution of the carbons under discussion confirm the bimodal character of the porous structure. The dominating pores have the radii $\sim 1 \mathrm{~nm}$ and $\sim 25 \mathrm{~nm}$ (Fig. 3c). It should be noted that these adsorbents possess a small number of macropores $\left(V_{\text {macro* }}\right.$, Table 1$)$, which is evidenced by a distinctly developed maximum on the $\mathrm{d} V /$ $\mathrm{d} R$ curves for carbons activated in the $\mathrm{He}$ and $\mathrm{He} / \mathrm{H}_{2}$ atmosphere in the area $\sim 80 \mathrm{~nm}$ (Fig. 3c). The isotherm shape and the course of volume distribution curve as well pore surfaces for the carbon $\mathrm{AC}-\mathrm{Ca}_{1}-\mathrm{He}^{*}$ (Fig. 3d) are similar to the curves of the $\mathrm{AC}-\mathrm{Ca}_{1}$ series active carbons (Fig. 3a, c). 


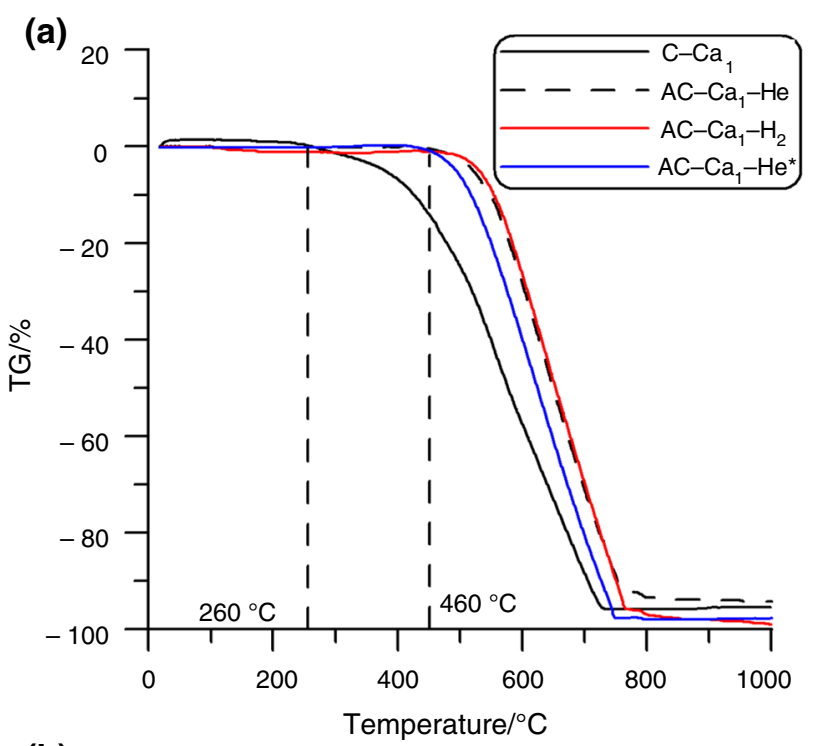

(b)

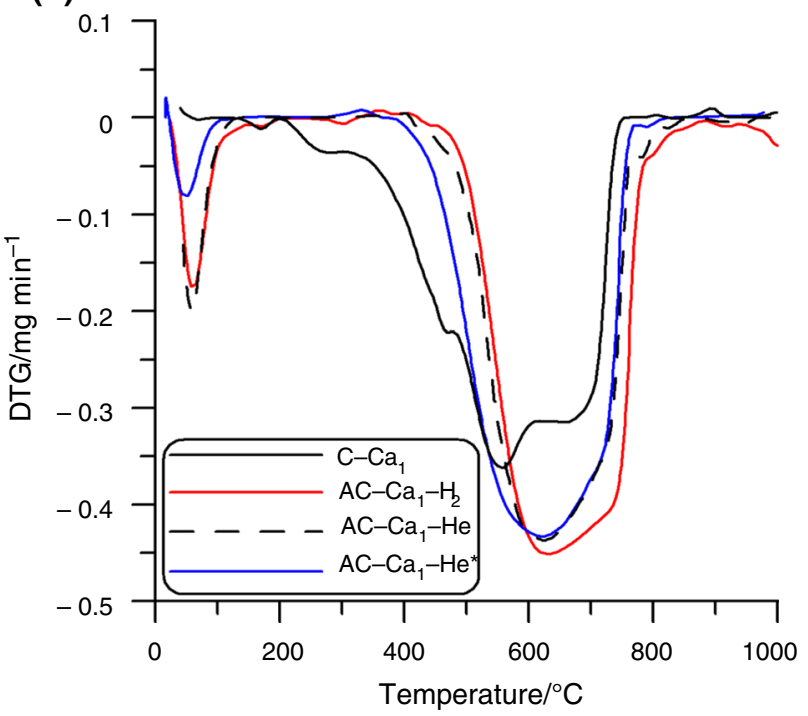

(c)

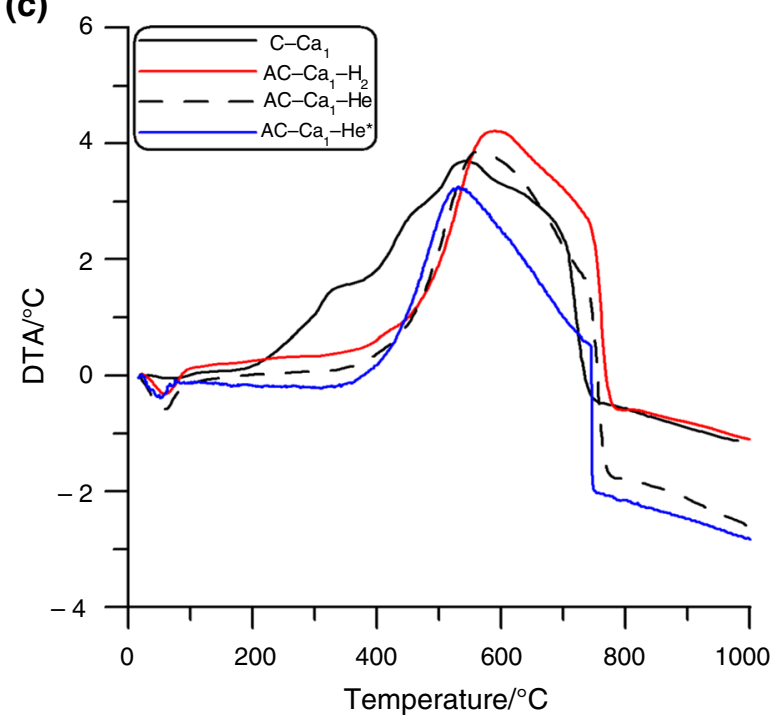

4Fig. 4 Course of the TG\% (a), DTG (b) and DTA (c) curves obtained for the carbons containing $5.6 \%$ of $\mathrm{Ca}^{2+}$ ions

\section{Thermal analysis}

Application of conventional thermal analysis made it possible to determine the carbon content and to estimate thermal stability of the studied materials. Figure 4 presents the TG (Fig. 4a), DTG (Fig. 4b) and DTA (Fig. 4c) curves obtained for the series of adsorbents with the maximum $\mathrm{Ca}^{2+}$ content.

As one can see (Fig. 4) the obtained curves have a similar course but the temperature of the initial mass loss (bend on the TG curve) shifts evidently toward higher temperatures with the increase in pyrolysis temperature. This indicates higher and higher thermal stability of carbons held at a temperature of $800{ }^{\circ} \mathrm{C}\left(\mathrm{AC}-\mathrm{Ca}_{1}-\mathrm{He}, \mathrm{AC}-\right.$ $\mathrm{Ca}_{1}-\mathrm{H}_{2}$ ).

The analysis of DTG curve (Fig. 4b) indicates the several-stage character of combustion in a wide range of temperatures, whereby pyrolysis at $800{ }^{\circ} \mathrm{C}$ causes narrowing of the DTG peak indicating better orientation of carbon layer. These changes can be also confirmed by the shape of DTA curves (Fig. 4c) disclosing poor thermal stability and heterogeneity of the studied material.

Additionally, Fig. 4 presents the curves registered for the $\mathrm{AC}-\mathrm{Ca}_{1}-\mathrm{He}^{*}$ material obtained at $730{ }^{\circ} \mathrm{C}$. The shape of curves is similar to the course of the curves obtained for the carbons $\mathrm{AC}-\mathrm{Ca}_{1}-\mathrm{He}$ and $\mathrm{AC}-\mathrm{Ca}_{1}-\mathrm{H}_{2}$. However, it is evident that carbon combustion proceeds at somewhat lower temperature which is due to a lower temperature of pyrolysis and thus poorer orientation of carbon in this material.

This trend was also found for the materials of a lower catalyst content whereby it is evident that carbon combustion temperatures increase with the increasing catalyst content. The respective values are presented in Table 3.

As follows from the investigations the activation atmosphere has a greater effect in the case of carbon of a smaller content of the catalyst (Table 3). The course of DTA curves (Fig. 4b) shows that the carbon formed in the $\mathrm{He}$ atmosphere is characterized by somewhat higher thermal stability which is also evidenced by the DTA curve (Fig. 4c) shift toward higher temperature.

\section{Quasi-isothermal investigations}

Figure 5 presents the exemplary curve of water thermodesorption under the quasi-isothermal conditions for the carbon AC-Ca $-\mathrm{Cl}$. A similar shape of curves was observed also for the other analyzed adsorbents. The course 
Table 3 Results of thermal analysis of the studied adsorbents

\begin{tabular}{lllllll}
\hline Sample & \multicolumn{7}{l}{$\Delta m \%$} & $\Delta T_{\mathrm{DTA}} /{ }^{\circ} \mathrm{C}$ & $T_{\mathrm{DTA}}^{\max } /{ }^{\circ} \mathrm{C}$ & \multicolumn{1}{c}{$\mathrm{C}_{\mathrm{C}} / \%$} \\
\cline { 2 - 4 } & $200-400{ }^{\circ} \mathrm{C}$ & $400-600{ }^{\circ} \mathrm{C}$ & $600-800{ }^{\circ} \mathrm{C}$ & & & \\
\hline $\mathrm{C}-\mathrm{Ca}_{004}$ & 2.3 & 56.1 & 0.9 & $272-699$ & 495 & 93.4 \\
$\mathrm{AC}-\mathrm{Ca}_{004}-\mathrm{He}$ & 2.1 & 30.3 & 28.6 & $307-483$ & 442 & 84.3 \\
$\mathrm{C}-\mathrm{Ca}_{01}$ & 8.4 & 70.3 & 0.2 & $386-563$ & 458 & 98.7 \\
$\mathrm{AC}-\mathrm{Ca}_{01}-\mathrm{H}_{2}$ & 2.3 & 69.3 & 2.8 & $272-734$ & 421 & 83.2 \\
$\mathrm{AC}-\mathrm{Ca}_{01}-\mathrm{He}$ & 6.1 & 67.2 & 3 & $173-644$ & 464 & 88.3 \\
$\mathrm{C}-\mathrm{Ca}_{1}$ & 5.6 & 51.1 & 0.4 & $483-604$ & 542 & 96 \\
$\mathrm{AC}-\mathrm{Ca}_{1}-\mathrm{H}_{2}$ & 0.4 & 25.2 & 1.7 & $365-765$ & 575 & 97.9 \\
$\mathrm{AC}-\mathrm{Ca}_{1}-\mathrm{He}$ & 0.1 & 36 & 0.6 & $330-767$ & 559 & 100 \\
$\mathrm{AC}-\mathrm{Ca}_{1}-\mathrm{He}$ & 0.4 & 41.6 & 0.2 & $320-728$ & 532 & 99.9 \\
\hline
\end{tabular}

of calcium ions, and it gets longer with the increase in $\mathrm{Ca}^{2+}$ ions content. This indicates that the obtained active carbons differ significantly in structure which is associated with the $\mathrm{Ca}^{2+}$ content in the studied material.

In the further stage desorption of water bound in pores proceeds up to a temperature of $\sim 110^{\circ} \mathrm{C}$. The multistage process visible on the TG curve is also marked on the DTG curve (Fig. 5a). There can be seen two distinctly developed minima evidencing the fastest stages of water mass loss. The DTA curve (Fig. 5b) also shows a broad peak of a few minima whose presence is a result of water evaporation (endothermal process) from the pores at different temperatures under quasi-isothermal conditions. The course of changes as one can see on the DTG curves is of multistage character. The curves for all studied carbons are characterized by a similar course.

Table 4 presents the values of water mass loss during thermodesorption under quasi-isothermal conditions. As proved (Fig. 5a) water undergoes desorption in two stages: "excess" water and water bound in pores. With the increase in $\mathrm{Ca}^{2+}$ ions content in the studied carbons, there are observed reduced contribution of "excess" water and regular increase in contribution of water bound in pores. Distinct differences in the contribution of excess water and that contained in pores in the defined carbon series $\left(\mathrm{Ca}_{004}\right.$; $\mathrm{Ca}_{01}$ and $\left.\mathrm{Ca}_{1}\right)$ are observed between carbonizates and activates. The contribution of excess water is much greater in carbonizates and that of water desorbed from pores smaller compared to the corresponding activates. This is due to the poor development and ordering of the surface of the carbonizates relative to the corresponding activates.

In the case of active carbon $\mathrm{AC}-\mathrm{Ca}_{1}-\mathrm{He} *$ contribution of individual kinds of water is somewhat different. The content of excess water is a bit higher and that in pores lower compared to the carbon $\mathrm{AC}-\mathrm{Ca}_{1}-\mathrm{He}$ which result from a lower activation temperature and a larger content of calcium ions (one stage pyrolysis without washing off 
Table 4 Contribution of water bound in pores and characteristics of water layers adsorbed on the surface of studied adsorbents

\begin{tabular}{llllrrrr}
\hline Sample & Water mass loss $/ \%$ & $\mathrm{TG}^{\mathrm{w}} / \mathrm{g}_{\mathrm{H}_{2} \mathrm{O}} \mathrm{g}_{\mathrm{ads}}^{-1}$ & $\mathrm{TG}^{\mathrm{s}} / \mathrm{g}_{\mathrm{H}_{2} \mathrm{O}} \mathrm{g}_{\mathrm{ads}}^{-1}$ & $n \mathrm{H}_{2} \mathrm{O}$ & $\Delta G_{\Sigma}^{\mathrm{w}} / \mathrm{kJ} \mathrm{mol}^{-1}$ & $\Delta G_{\Sigma}^{\mathrm{s}} / \mathrm{kJ} \mathrm{mol}^{-1}$ & $\mathrm{C}_{\mathrm{H}_{2} \mathrm{O}}^{\mathrm{Oax}} / \mathrm{g} \mathrm{g}^{-1}$ \\
\hline $\mathrm{C}-\mathrm{Ca}_{004}$ & 12.4 & 0.95 & 0.13 & 7878.5 & 6020.1 & 73.0 & 1.03 \\
$\mathrm{AC}-\mathrm{Ca}_{004}-\mathrm{He}$ & 21.5 & 0.67 & 0.18 & $10,423.1$ & 5013.7 & 310.6 & 0.81 \\
$\mathrm{AC}-\mathrm{Ca}_{004}-\mathrm{H}_{2}$ & 18.3 & 0.71 & 0.16 & $234,867.3$ & 5204.8 & 273.0 & 0.85 \\
$\mathrm{C}-\mathrm{Ca}_{01}$ & 14.9 & 0.86 & 0.15 & 8318.4 & 5824.5 & 13.2 & 1.00 \\
$\mathrm{AC}-\mathrm{Ca}_{01}-\mathrm{He}$ & 31.1 & 1.21 & 0.55 & 105.7 & $10,349.1$ & 507.5 & 1.69 \\
$\mathrm{AC}-\mathrm{Ca}_{01}-\mathrm{H}_{2}$ & 34.5 & 0.90 & 0.47 & 95.3 & 8355.1 & 459.7 & 1.37 \\
$\mathrm{C}-\mathrm{Ca}_{1}$ & 24.4 & 0.59 & 0.19 & $12,037.3$ & 4256.7 & 36.6 & 0.74 \\
$\mathrm{AC}-\mathrm{Ca}_{1}-\mathrm{He}$ & 50.5 & 1.18 & 1.21 & 110.5 & $14,623.2$ & 318.1 & 2.36 \\
$\mathrm{AC}-\mathrm{Ca}_{1}-\mathrm{H}_{2}$ & 58.2 & 1.00 & 1.39 & 59.4 & $14,554.8$ & 355.2 & 2.37 \\
$\mathrm{AC}-\mathrm{Ca}_{1}-\mathrm{He}^{*}$ & 46.5 & 1.34 & 1.17 & 64.7 & $15,380.5$ & 437.9 & 2.51 \\
\hline
\end{tabular}

$\mathrm{TG}^{\mathrm{W}}\left[\mathrm{g}_{\mathrm{H}_{2} \mathrm{O}} \mathrm{g}_{\text {ads }}^{-1}\right]$ —amount of weakly bound water; $\mathrm{TG}^{\mathrm{s}}\left[\mathrm{g}_{\mathrm{H}_{2} \mathrm{O}} \mathrm{g}_{\text {ads }}^{-1}\right]$ —amount of strongly bound water in pores; $n \mathrm{H}_{2} \mathrm{O}$-number of statistical monolayers of water; $\Delta G_{\Sigma}^{\mathrm{w}} \mathrm{kJ} \mathrm{mol}^{-1}$ —surface free energy at the adsorbent/weakly bound water interface; $\Delta G_{\Sigma}^{\mathrm{s}} \mathrm{kJ}$ mol $^{-1}$ — surface free energy at the adsorbent/strongly bound water interface; $\mathrm{C}_{\mathrm{H}_{2} \mathrm{O}}^{\max } \mathrm{g} \mathrm{g}^{-1}$-maximal concentration of adsorbed water

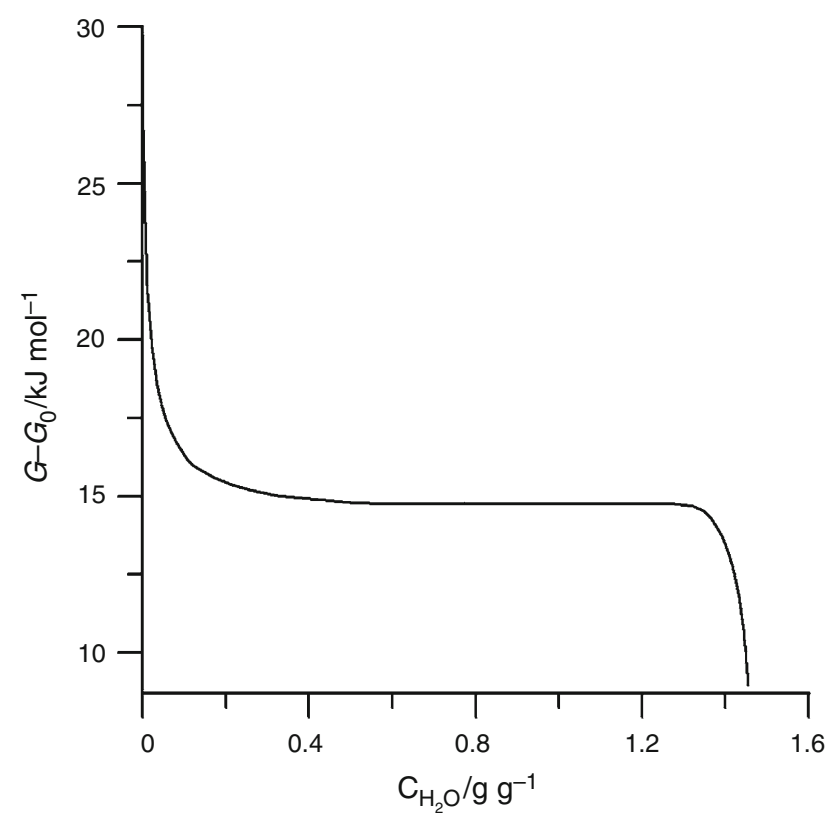

Fig. 6 Dependence of the changes of $\Delta G$ values on the concentration of water adsorbed on the $\mathrm{AC}-\mathrm{Ca}_{01}-\mathrm{H}_{2}$

unbound $\mathrm{Ca}^{2+}$ ions) which can block the pores of the obtained carbon.

As follows from the obtained results the more effective activation is, the larger calcium ions content is in the initial ion-exchange resin.

As commonly known, a necessary condition, which must be fulfilled for evaporation of adsorbed water under equilibrium conditions, is the equality of the free energy of adsorbed water and that of water in the gas phase. As the thermodynamic functions of the water vapor are tabulated over a wide temperature range, changes in the free energy of water can be calculated using Eq. 3 [29]:

$\Delta G=G-G_{\mathrm{o}}=-0.197\left(T-T_{\mathrm{o}}\right)$

where $T_{\mathrm{o}}$ is the temperature chosen as the standard.

The dependencies of changes in $\Delta G$ on the concentration of water adsorbed on $\mathrm{AC}-\mathrm{Ca}_{01}-\mathrm{H}_{2}$ are shown in Fig. 6. This figure presents the $\Delta G\left(\mathrm{C}_{\mathrm{H}_{2} \mathrm{O}}\right)$ curve over the whole range of investigated surface concentrations of water. This dependence was used to determine the characteristics of water adsorbed on the surface of the tested materials presented in Table 4.

Figure 7 presents the exemplary dependences of the active radius of an evaporating drop on the adsorbed water concentration (Fig. 7a) and the $\mathrm{d} G / \mathrm{d} M$ dependence under the conditions of insignificant surface filling with adsorbed water on the concentration of adsorbed water for the carbon $\mathrm{AC}-\mathrm{Ca}_{1}-\mathrm{He}$. The shape of curves (Fig. 7a) indicates that in the initial stage of water thermodesorption (large $\mathrm{C}_{\mathrm{H}_{2} \mathrm{O}}$, low temperature) the effective radius of the evaporating drop is small and with the temperature increase it grows to the value determining the radius of dominating pores, $R_{\mathrm{dom}}$. Further increase in temperature results in reduction in both adsorbed water concentration and size of effective radius of the evaporating drop. For the studied adsorbents the maximal concentration of adsorbed water $\left(\mathrm{C}_{\mathrm{H}_{2} \mathrm{O}}\right)$ increases with the increasing content of $\mathrm{Ca}^{2+}$ ions (Table 4). The largest values $\mathrm{C}_{\mathrm{H}_{2} \mathrm{O}}$ were registered for the carbon $\mathrm{AC}-\mathrm{Ca}_{1}-\mathrm{He}^{*}$ (Table 4). In all cases the obtained profiles remind the Gauss curves in shape (bell-shaped). As follows from the obtained results the carbon sorption capacity toward water increases with the increasing $\mathrm{Ca}^{2+}$ ions content. This can be associated with the more intense porous structure 


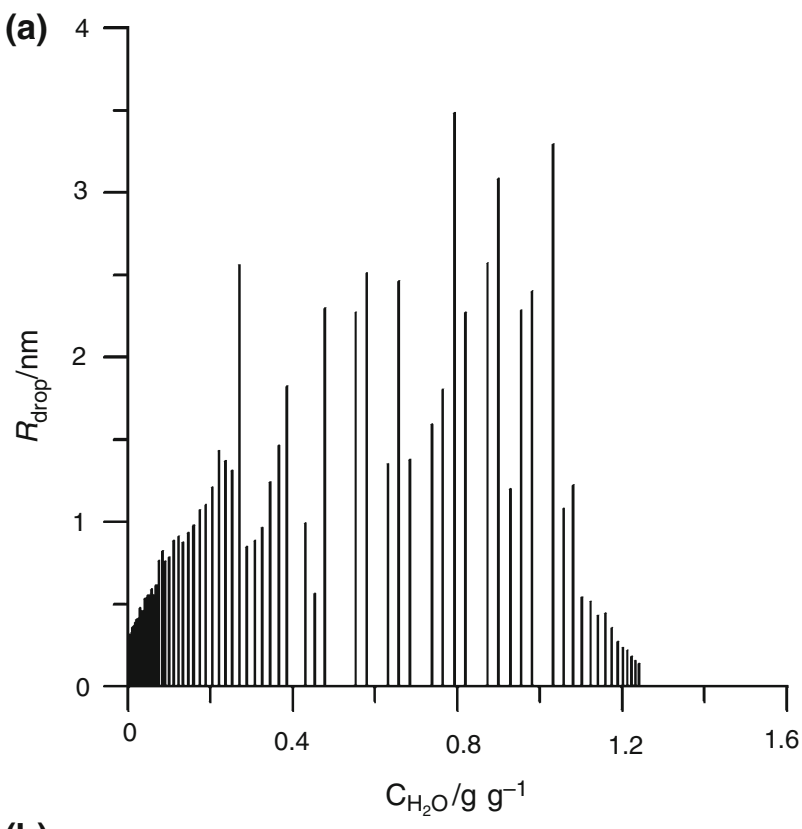

(b)

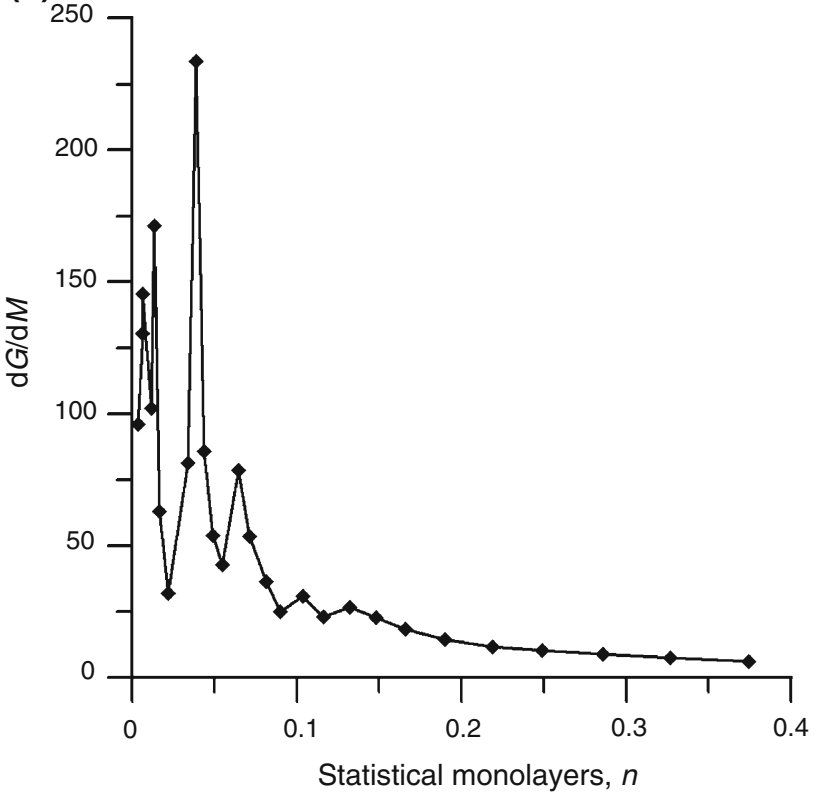

Fig. 7 Dependences of the effective radius of the evaporating drop on the concentration of the adsorbed water (a) and $\mathrm{d} G / \mathrm{d} M$ with small filling of the surface with the adsorbed water on the statistical monolayers number (b) for the carbon $\mathrm{AC}-\mathrm{Ca}_{01}-\mathrm{H}_{2}$

development and an increasing number of heteroatoms (Ca) in individual series of carbon.

Figure $7 \mathrm{~b}$ presents the exemplary dependences of system free energy changes during water evaporation from the surface under the conditions of low coverage with water $(\mathrm{d} G / \mathrm{d} M)$ in the function of a number of water statistical monolayers. The value $\mathrm{d} G / \mathrm{d} M$ can be used as an analogue of the chemical potential for description of water thermodesorption under the isobar conditions [23]. The dependences show single maxima (Fig. 7b) indicating the formation of water clusters of similar structure on the adsorbent surface. In turn, multiple maxima (particularly for the adsorbents of low content of $\mathrm{Ca}^{2+}$ ions, series $\mathrm{AC}-$ $\mathrm{Ca}_{004}$ ) indicate a poorly arranged structure of water layers.

Table 4 presents the characteristics of water layers adsorbed on the surface of studied active carbons. As follows from the data in Table 4, the total amount of adsorbed water increases with the increasing content of $\mathrm{Ca}^{2+}$ ions (series $\mathrm{Ca}_{004}<\mathrm{Ca}_{01}<\mathrm{Ca}_{1}$ ). This refers particularly to the strongly bound water $\left(\mathrm{TG}^{\mathrm{s}}\right)$. However, the analysis of the data concerning the weakly bound water, $\mathrm{TG}^{\mathrm{w}}$, in the case of studied materials is not reliable due to significant and irreproducible excess of volumetric water which is different for individual samples. Such tendency is also the changes of the total concentration of adsorbed water $\left(\mathrm{C}_{\mathrm{H}_{2} \mathrm{O}}^{\max }\right)$. For active carbons these values increase with the increasing $\mathrm{Ca}^{2+}$ ions content, but for carbonizates this dependence is reverse, i.e., the value $\mathrm{C}_{\mathrm{H}_{2} \mathrm{O}}^{\max }$ decreases with the increasing $\mathrm{Ca}^{2+}$ content. Moreover, for the $\mathrm{AC}-\mathrm{Ca}_{01}$ and $\mathrm{AC}-\mathrm{Ca}_{1}$ series adsorbents the $\mathrm{C}_{\mathrm{H}_{2} \mathrm{O}}^{\max }$ values are higher for active carbons than for carbonizates. This dependence is also found for strongly bound water $\left(\mathrm{TG}^{\mathrm{s}}\right)$ which is associated with more and more intensive development of surface and larger volume of active carbon sorption pores compared to the corresponding carbonizates. Such changes can also be due to surface polarity changes of studied materials which also affects strength of the interactions between the $\mathrm{H}_{2} \mathrm{O}$ molecules and the adsorbent surface.

\section{Conclusions}

The surfaces of activated carbons prepared from ion-exchange resins in the cationic form are complex with respect to both their texture (characterized by developed microand mesoporosity) and chemistry. The $\mathrm{Ca}^{2+}$ ions content influences positively on the structural parameters of carbons. The best parameters were observed for the carbons of maximal $\mathrm{Ca}^{2+}$ content. It was shown that the atmosphere of pyrolysis has also impact on the obtained carbon characteristics. In the case of carbon of maximal $\mathrm{Ca}^{2+}$ ions content, the addition of $\mathrm{H}_{2}\left(\mathrm{He} / \mathrm{H}_{2}\right)$ to pyrolysis atmosphere is favorable.

The surfaces of these carbon adsorbents possess a complex character. The evidence of this is the increasing thermal stability and number of adsorption sites (responsible for water adsorption) with the $\mathrm{Ca}^{2+}$ content increasing. These adsorbents show complex porous structures over micro- and mesopore ranges, which causes changes in evaporation of water drop profiles, number and structure of 
water monolayers and energetic characteristics of adsorbed water.

The values of specific surface area and pore volume indicate that the synthetic activated carbons can be utilized for different purposes. Additional specific modification can change their porosity, specific surface area and surface character.

Acknowledgements The research was partly carried out with the equipment purchased owing to the financial support of the European Regional Development Fund in the framework of the Polish Innovation Economy Operational Program (Contract No. POIG.02.01.0006-024/09 Center of Functional Nanomaterials).

Open Access This article is distributed under the terms of the Creative Commons Attribution 4.0 International License (http://creative commons.org/licenses/by/4.0/), which permits unrestricted use, distribution, and reproduction in any medium, provided you give appropriate credit to the original author(s) and the source, provide a link to the Creative Commons license, and indicate if changes were made.

\section{References}

1. Podkościelna B, Kołodyńska D. A new type of cation-exchange polymeric microspheres with pendant methylenethiol groups. Polym Adv Technol. 2013;24(10):866-72.

2. Podkościelna B. The use of bis[4(2-hydroxy-3-methacryloyloxypropoxy)phenyl] sulfide in preparation of microspheres with pendant amine groups as a heavy metal sorbent. Sep Sci Technol. 2013;48(11):1699-708.

3. Podkościelna B, Gil M, Bartnicki A, Fila K. Studies on the synthesis and physico-chemical properties of the new polymeric ion exchangers with sulphur groups. Adsorpt Sci Technol. 2017;35(5-6):413-21.

4. Makomaski G. Porous structure and thermal properties of carbon adsorbents from pitch-polymer compositions. J Therm Anal Calorim. 2018;133:1345-52.

5. Skubiszewska-Zięba J, Leboda R, Charmas B, Grzegorczyk W, Szmigielski R. On the preparation of synthetic carbon adsorbents using the sulfonated ion exchange resin Duolite C-20. J Therm Anal Calorim. 2006;86(1):187-94.

6. Gun'ko VM, Leboda R, Skubiszewska-Zięba J, Charmas B, Oleszczuk P. Carbon adsorbents from waste ion exchange resins. Carbon. 2005;43:1143-50.

7. Bratek K, Bratek W, Kułażyński M. Carbon adsorbents from waste ion-exchange resin. Carbon. 2002;40:2213-20.

8. Serp P, Machado B. Nanostructured carbon materials for catalysis. RSC catalysis series no. 23. London: Royal Society of Chemistry; 2015.

9. Sircar S, Golden TC, Rao MB. Activated carbon for gas separation and storage. Carbon. 1996;34(1):1-12.

10. Cook TL, Komodromos C, Quinn DE, Ragan S. Adsorbent storage for natural gas vehicle. In: Burchell TD, editor. Carbon materials for advanced technologies. Pergamon: Oxford; 1999. p. 269-302
11. Paulik F, Paulik J. Kinetic studies of thermal decomposition reactions under quasi-isothermal and quasi-isobaric conditions by means of the derivatograph. Thermochim Acta. 1972;4:189-98.

12. Paulik F, Paulik J. Investigation under quasi-isothermal and quasi-isobaric conditions by means of the derivatograph. $\mathrm{J}$ Therm Anal. 1973;5:253-70.

13. Rouquerol J. Critical examination of several problems typically found in the kinetic study of thermal decomposition under vacuum. J Therm Anal. 1973;5:203-16.

14. Bazan A, Nowicki P, Półrolniczak P, Pietrzak R. Thermal analysis of activated carbon obtained from residue after supercritical extraction of hops. J Therm Anal Calorim. 2016;125:1199-204.

15. Gun'ko VM, Leboda R, Skubiszewska-Zięba J, Zarko VI, Goncharuk EV, Charmas B, Mikhalovsky SV. Comparative analysis of porous structure and adsorption properties of activated carbons. Him Fiz ta Tehnol Poverhni. 2012;3(2):123-32.

16. El-Naggar AY. Thermal analysis of the modified, coated and bonded alumina surfaces. J Emerg Trends Eng Appl Sci. 2014;5(1):30-4.

17. Odlyha M, Scott R, Simpson C. The hydroxyl content of silica gel. J Therm Anal Calorim. 1993;40(3):1197-212.

18. Zielińska A, Oleszczuk P, Charmas B, Skubiszewska-Zięba J, Pasieczna-Patkowska S. Effect of sewage sludge properties on the biochar characteristic. J Anal Appl Pyrolysis. 2015;112:201-13.

19. Skubiszewska-Zięba J, Charmas B, Leboda R, Staszczuk P, Kowalczyk P, Oleszczuk P. Effect of hydrothermal modification on the porous structural and thermal properties of carbon-silica adsorbents (carbosils). Mater Chem Phys. 2002;78(2):486-94.

20. Charmas B. Structural and thermal characteristics of Ni doped carbosils prepared by mechanochemistry. J Therm Anal Calorim. 2015;120(2):1347-54.

21. Charmas B, Skubiszewska-Zięba J, Leboda R, Turov VV, Kowalczyk P. Effect of hydrothermal treatment on the structure of water layers in carbosils suspensions. Colloids Surf A. 2003;221:91-9.

22. Gregg SJ, Sing KSW. Adsorption, surface area and porosity. 2nd ed. London: Academic Press; 1982.

23. Gun'ko VM, Mikhalovsky SV. Evaluation of slitlike porosity of carbon adsorbents. Carbon. 2004;42:843-9.

24. Gun'ko VM, Turov VV. Nuclear magnetic resonance studies of interfacial phenomena. San Diego: Taylor \& Francis; 2013.

25. Gunko VM, Turov VV, Leboda R, Skubiszewska-Zięba J, Charmas B. Confined space effects driving to heterogenization of solutions at the interfaces. Adsorption. 2013;19:305-21.

26. Gun'ko VM, Do DD. Characterisation of pore structure of carbon adsorbents using regularisation procedure. Colloids Surf A. 2001;19:71-83.

27. Skubiszewska-Zięba J, Charmas B, Leboda R, Tertykh VA, Yanishpolskii VV. Complex investigations of structural and thermal properties of silica-titania adsorbents. J Therm Anal Calorim. 2012;108:1085-92.

28. Turov VV, Leboda R, Skubiszewska-Zięba J, Charmas B. Application of quasi-isothermal thermogravimetry for estimation of some properties of hydration layers in mesoporous adsorbents. Colloids Surf A. 2001;181:1-9.

29. Glushko VM. Handbook in thermodynamic properties of individual substances. Moscow: Nauka; 1978. 